\title{
Effect of Long Protocol versus Short Protocol of Metformin Therapy in Pregnancy Outcomes in Polycystic Ovarian Syndrome - A Comparative Study
}

\author{
Authors \\ Arya R Nair ${ }^{1}$, Bindu $\mathrm{M}^{2}$, Sunil K Menon ${ }^{3}$, Archana $\mathrm{S}^{4}$ \\ 1,2,4 Dept of Obstetrics and Gynaecology, Jubilee Mission Medical College and Research Institute, \\ Thrissur, Kerala \\ ${ }^{1}$ Phone No. 9947961880. Email- aryanaircmc@gmail.com \\ ${ }^{3}$ Dept of Endocrinology, Jubilee Mission Medical College and Research Institute, Thrissur, Kerala
}

\begin{abstract}
Background: Women with polycystic ovarian syndrome (PCOS) often have insulin resistance and hyperinsulinaemia and may therefore be at an increased risk for gestational diabetes mellitus (GDM). Metformin is widely prescribed to pregnant women with PCOS in an attempt to reduce pregnancy complications. Metformin is not approved for this indication, and evidence for this practice is lacking

Aim: the objective of this study was to compare the pregnancy outcomes if metformin was continued till delivery in pregnant PCOS patientsto the outcomes if metformin was discontinued at 12 weeks.

Materials and methods: this single institution study included 81 women diagnosed with PCOS who conceived with metformin and randomised into two groups, group 1 who continues metformin till delivery and group 2 who discontinued metformin at 12 weeks. Obstetrical outcomes measured were GDM, Gestational hypertension, fetal growth restriction (FGR) and preterm delivery.

Results: Gestational hypertension was seen in $25 \%$ in group 1 and $33 \%$ in group $2.20 \%$ patients were found to have GDM in group 1 and 33\% in group 2..Preterm labour rate in group 1 and group 2 were 25\% and $33 \%$ respectively. Incidence of FGR was similar in both groups, $18 \%$.

Conclusion: Metformin appeared to reduce the incidence of GDM, especially need for insulin initiation if taken throughout pregnancy. It also appeared to reduce the incidence of hypertensive complications and preterm labour in this study. Metformin appeared to have no correlation to fetal growth restriction as evidenced by this study.

Keywords: Polycystic ovarian syndrome, Metformin, Gestational hypertension, Gestational Diabetes Mellitus, Fetal Growth Restriction, Preterm Labour.
\end{abstract}

\section{Introduction}

Polycystic ovarian syndrome is a condition associated with chronic anovulation and hyperandrogenemia. It is considered to be the commonest cause of anovulatory infertility and affects $6-10 \%$ of women of reproductive age. Many 
women with PCOS have insulin resistance with elevated insulin levels and are predisposed to developing various complications during pregnancy such as gestational diabetes, pregnancy induced hypertension and placental vascular insufficiency. Hyperinsulinemia is also believed to play a key role in implantation failure due to its antagonistic effect on glycodelin in endometrium and results in increasing rates of miscarriage in women with PCOS compared to controls $1,2,3,4,5$.

Metformin is a biguanide, oral hypoglycemic drug that improves tissue sensitivity to insulin while decreasing insulin levels and inhibiting hepatic glucose production. When used in patients with PCOS metformin reduces luteinizing hormone (LH),sex hormone binding globulins and ovarian androgens and also corrects hyperinsulinemia $6,7,8,9,10$. Metformin is considered to be safe, effective and rational for the metabolic and endocrine abnormalities in PCOS. Its use as a first line agent for ovulation induction has been extensively investigated and has been found to increase the likelihood of ovulation and pregnancy rates, particularly in women who have clomiphene resistance $^{11,12,13}$. Metformin is a category B drug for use in pregnancy and in recent years its use in pregnancy has become increasingly popular. As there are no guidelines for its continuous use in pregnancy, the duration of treatment is therefore randomly selected by physicians based on their experience..During the last decade, sever alretrospective and nonrandomized studies have reported beneficial effects of metformin on pregnancy loss and pregnancy complications, in particular gestational diabetes mellitus (GDM). This study aims to evaluate pregnancy outcomes in such cases if metformin is continued till delivery.

\section{Materials and Methods}

This single institutional study was conducted in the time period NOVEMBER 2013 - APRIL 2015. PCOS diagnosed according to Rotterdam criteria. 2 out of 3 must be present. These include menstrual irregularity, hyperandrogenemia (clinical or biochemical), ultrasound morphology of polycystic ovaries (presence of more than 12 small follicles measuring $2-9 \mathrm{~mm}$ in subcortical region), total ovarian volume more than $10 \mathrm{ml}$ after exclusion of other endocrinopathies and hyperandrogenemia. The study included 81 women aged 18- 45 years with PCOS who conceived while on metformin therapy with or without other ovulation-inducing agents such as clomiphene citrate and gonadotrophins. Metformin was continued till 12 weeks. Then metformin was continued till delivery in 39 women selected randomly. Written informed consent was taken from each patient .The 39 women who continued metformin till delivery constituted group 1. The rest of 42 women who stopped metformin at 12 weeks was group 2. The exclusion criteria was Known liver disease or ALAT > 90 nmol/L, Known renal disease or creatinine $>110$ micromol/L, Diabetes mellitus, Alcohol or drug abuse, Peroral steroid treatment, Cimetidine, anticoagulant or erythromycin treatment at time of inclusion.All the selected women were followed up and at every visit relevant history was taken including medical history, family history etc. the following findings are noted:General examination, Weight, Blood pressure and Obstetric examination to assess fetal growth. The following investigations are done: Baseline $\mathrm{Hb}$, blood group and $\mathrm{Rh}$, screening, RFT, LFT, HbA1C, FBS/PPBS, TSH, 75 GM GTT between 24-28 weeks, Serial ultrasounds to monitor fetal growth and 24 hour urine protein if required. The outcome criteria is:

- Gestational diabetes based on 75gm glucose tolerance test between 24-28 weeks. The cut off value is taken as FBS $<92,1 \mathrm{HR}<180$ and $2 \mathrm{HR}<153$. Any one abnormal value is diagnosed as GDM

- Gestational hypertension by BP more than $140 / 90$ with or without proteinurea (> 0.3 gm in 24 hours) after 20 weeks on two separate occasions at least 6 hours apart.

- Preterm labour- between 24 -36 weeks

- Fetal growth restriction-abdominal circumference less than $5^{\text {th }}$ centile for that gestation on ultrasound. 


\section{JMSCR Vol||04||Issue ||05||Page 10518-10524||May}

Statistical Methods; Descriptive and inferential statistical analysis has been carried out in the present study. Student $t$ test (two tailed, independent) has been used to find the significance of study parameters on continuous scale between two groups (Inter group analysis) on metric parameters. Chi-square/ Fisher Exact test has been used to find the significance of study parameters on categorical scale between two or more groups. The Statistical software namely SAS 9.2, SPSS 15.0, Stata 10.1, MedCalc 9.0.1, Systat 12.0 and R environment ver.2.11.1 were used for the analysis of the data.

\section{Results}

There were 39 patients in group 1 and 42 in group 2 . They were followed up till delivery and relevant findings were recorded.

The study variables are shown in table 1. Majority of the patients were in the age group 20-30. 95\% in group 2 and $84 \%$ in group 1 belonged to this age. $60 \%$ patients were primis. Both groups were similar in this aspect.Most of the patients (50\%) were of normal BMI. $45 \%$ were overweight.

Table 1: comparison of study variables

\begin{tabular}{|l|l|l|l|}
\hline & Group I & \multicolumn{1}{|c|}{ Group II } & $\begin{array}{l}\mathrm{p}- \\
\text { value }\end{array}$ \\
\hline Age in years & $26.36 \pm 3.96$ & $25.45 \pm 3.67$ & 0.288 \\
\hline $\begin{array}{l}\text { Period of } \\
\text { infertility in } \\
\text { years }\end{array}$ & $3.88 \pm 3.79$ & $2.69 \pm 1.52$ & 0.063 \\
\hline $\begin{array}{l}\text { Pre pregnancy } \\
\text { BMI in kg/m2 }\end{array}$ & $27.56 \pm 2.69$ & $24.60 \pm 2.95$ & 0.001 \\
\hline FBS in mg/dl & $96.69 \pm 7.33$ & $101.26 \pm 15.32$ & 0.095 \\
\hline $\begin{array}{l}\text { PPBS in } \\
\text { mg/dl }\end{array}$ & $121.00 \pm 11.61$ & $124.67 \pm 19.07$ & 0.304 \\
\hline SBP in mmHg & $133.33 \pm 15.62$ & $137.45 \pm 17.99$ & 0.276 \\
\hline $\begin{array}{l}\text { DBP in } \\
\mathrm{mmHg}\end{array}$ & $84.87 \pm 10.23$ & $86.45 \pm 12.51$ & 0.537 \\
\hline $\begin{array}{l}\text { Birth weight } \\
\text { in kg }\end{array}$ & $2.74 \pm 0.58$ & $2.71 \pm 0.70$ & 0.830 \\
\hline
\end{tabular}

Most of the patients (around 73\%) conceived with just metformin and weight reduction. $27 \%$ required $\mathrm{CC}$ in addition

The incidence of pre-eclampsia was $7 \%$ in group 1 and $12 \%$ in group 2(table 2)
Table 2: Pre Eclampsia in two groups of patients studied

\begin{tabular}{|l|l|l|l|}
\hline $\begin{array}{l}\text { Pre } \\
\text { Eclampsia }\end{array}$ & Group I & Group II & Total \\
\hline No & $36(92.3 \%)$ & $37(88.1 \%)$ & $73(90.1 \%)$ \\
\hline Yes & $3(7.7 \%)$ & $5(11.9 \%)$ & $8(9.9 \%)$ \\
\hline Total & $39(100 \%)$ & $42(100 \%)$ & $81(100 \%)$ \\
\hline
\end{tabular}

$\mathrm{P}=0.714$, Not significant, Chi-Square test

The prevalence of FGR was similar in both groups, $17 \%$ in group 1 and $19 \%$ in group 2 (table 3 )

Table 3: Incidence of FGR in two groups of patients studied

\begin{tabular}{|l|l|l|l|}
\hline FGR & Group I & Group II & Total \\
\hline No & $32(82.1 \%)$ & $34(81 \%)$ & $66(81.5 \%)$ \\
\hline Yes & $7(17.9 \%)$ & $8(19 \%)$ & $15(18.5 \%)$ \\
\hline Total & $39(100 \%)$ & $42(100 \%)$ & $81(100 \%)$ \\
\hline
\end{tabular}

$\mathrm{P}=0.899$, Not Significant, Chi-Square test

$20 \%$ patients were found to have GDM in group 1 whereas 33\% had GDM in group 2. Of these in group $110 \%$ required insulin and $20 \%$ in group 2 required insulin (table 4)

Table 4: Incidence of GDM in two groups of patients studied

\begin{tabular}{|l|l|l|l|l|}
\hline GDM & $\begin{array}{l}\text { Group I } \\
(\mathrm{n}=39)\end{array}$ & $\begin{array}{l}\text { Group II } \\
(\mathrm{n}=42)\end{array}$ & $\begin{array}{l}\text { Total } \\
(\mathrm{n}=81)\end{array}$ & $\begin{array}{l}\mathrm{P} \\
\text { value }\end{array}$ \\
\hline $\begin{array}{l}\text { GDM ON } \\
\text { DIET AND } \\
\text { METFORMIN }\end{array}$ & $4(10.3 \%)$ & $5(11.9 \%)$ & $9(11.1 \%)$ & 0.814 \\
\hline $\begin{array}{l}\text { GDM On } \\
\text { Insulin }\end{array}$ & $4(10.3 \%)$ & $9(21.4 \%)$ & $13(16 \%)$ & 0.171 \\
\hline
\end{tabular}

Macrosomia was there in around $6 \%$ of the population, majority of which was in group 2

Gestational hypertension was seen in $25 \%$ in group 1 and $33 \%$ in group 2. Severity of gestational hypertension was found to be similar (table 5) 
Table 5: Incidence of Hypertension in two groups of patients studied

\begin{tabular}{|l|l|l|l|l|}
\hline Hypertension & $\begin{array}{l}\text { Group I } \\
(\mathrm{n}=39)\end{array}$ & $\begin{array}{l}\text { Group II } \\
(\mathrm{n}=42)\end{array}$ & $\begin{array}{l}\text { Total } \\
(\mathrm{n}=81)\end{array}$ & $\begin{array}{l}\mathrm{P} \\
\text { value }\end{array}$ \\
\hline $\begin{array}{l}\text { Hypertension } \\
\text { on 1 drug }\end{array}$ & $7(17.9 \%)$ & $9(21.4 \%)$ & $16(19.8 \%)$ & 0.694 \\
\hline $\begin{array}{l}\text { Hypertension } \\
\text { on more than } \\
\text { 1 Drug }\end{array}$ & $3(7.7 \%)$ & $5(11.9 \%)$ & $8(9.9 \%)$ & 0.525 \\
\hline
\end{tabular}

Preterm labour rates in group 1 and group 2 were $25 \%$ and $33 \%$ respectively (table 6 )

Table 6: Occurance of Pre-term labour in two groups of patients studied

\begin{tabular}{|l|l|l|l|}
\hline $\begin{array}{l}\text { Occurance } \\
\text { of Pre-term } \\
\text { labour }\end{array}$ & Group I & Group II & Total \\
\hline No & $29(74.4 \%)$ & $28(66.7 \%)$ & $57(70.4 \%)$ \\
\hline $28-32$ weeks & $7(17.9 \%)$ & $12(28.6 \%)$ & $19(23.5 \%)$ \\
\hline $32-36$ weeks & $3(7.7 \%)$ & $2(4.8 \%)$ & $5(6.2 \%)$ \\
\hline Total & $39(100 \%)$ & $42(100 \%)$ & $81(100 \%)$ \\
\hline
\end{tabular}

$\mathrm{P}=0.589$, Not significant, Fisher Exact test

$67 \%$ were full term deliveries. Preterm delivery incidence was similar in both groups. Vaginal delivery was the predominant mode of delivery $(60 \%)$. It was similar in both groups. The mean birth weight was similar around $2.7 \mathrm{~kg}$.

\section{Discussion}

The use of metformin in reproductive medicine has exploded since clinical trials showed that a metabolic medication improved reproductive abnormalities in women with polycystic ovary syndrome. Metformin soon became an essential element for restoring ovulation, curing infertility, preventing pregnancy loss, and reducing pregnancy complications such as gestational diabetes mellitus (GDM), preeclampsia, and preterm labor, all of which were linked to insulin resistance and systemic inflammation in PCOS. As for the safety profile, studies have reported that the use of metformin in the treatment of GDM had no increased risk of perinatal complications, which settled a previous controversy regarding metformin safety in pregnancy.
This study focused on mainly four outcomes

- Development of gestational diabetes mellitus

- Development of gestational hypertension

- Occurrence of preterm labour

- Development of fetal growth restriction

This study shows a slightly decreased prevalence of hypertension in PCOS patients who continued metformin till their delivery. The severity of hypertension does not seem dependent on metformin. Development of pre-eclampsia was comparable in both groups.

PCOS appears to increase the risk of gestational hypertension and pre eclampsia by insulin resistance. Metformin can reduce these complications by reducing IR. However studies are yet to prove the role of metformin in $r$ educing hypertensive disorders in pregnancy ${ }^{14,15}$.

More than a decade ago it was demonstrated that GDM in women with PCOS is $8 \%$ compared to $3 \%$ in controls. Subsequent studies from the Asian subcontinent have shown a higher rate of GDM $(20-25 \%)$ than in controls $(9 \%)$. This is probably because of the high prevalence of insulin resistance in Asian women. Insulin resistance is three-fold increase in pregnancy, and also plays a crucial role in development of hypertension in pregnancy and subsequent fetal growth-related problems secondary to placental vascular insufficiency. ${ }^{16,17,18}$

It is well known that hyperinsulinemia, insulin resistance and obesity are common in women with PCOS. It has been well appreciated that continuation of metformin imparts a more therapeutic effect on GDM requiring insulin treatment compared to preventive effects. Current study results are comparable to those of Norman et al., Hague et al., Legro and Glucek et al. who have shown a significant reduction of GDM and better control with continued metformin treatment ${ }^{[19],[20],[21]}$.In general, the number of studies reporting on the use of metformin in women with type 2 diabetes or GDM is still small. One retrospective study reported increased rates of preeclampsia and perinatal loss in a cohort of women with GDM or type 2 diabetes treated with metformin compared with a reference group treated 
with insulin, but the groups were not well matched for age or body mass index. In the study of PCOS patients treated with metformin, the rate of preeclampsia did not differ compared with healthy control women even though women with PCOS were older and more obese. There are two randomized studies comparing insulin and metformin in the treatment of GDM. One study with a small number of patients suggests that metformin is an effective alternative to insulin. ${ }^{19,20}$

This study shows a higher incidence of preterm labour in those who discontinued metformin after 12 weeks. Previous studies have not shown any effect of metformin in preterm labour. Several studies have assessed the association of metformin and preterm labour in women with PCOS, of which few showed that metformin statistically reduced preterm labour rates. One RCT showed no difference in preterm labour rates with use of metformin throughout pregnancy compared to eight weeks, and one retrospective study showed higher preterm rates compared to normal populations ${ }^{13,14}$. Incidence of FGR was $17 \%$ in group 1 and $19 \%$ in group 2. Based on this study there is no effect of continuing metformin to reduce FGR. Previously study by FauziaHaq Nawaz, Roha Khalid, TahiraNaru and Javed Rizvi showed reduced incidence of FGR in women on metformin[22].

\section{Conclusion}

The conclusions drawn from this study are the following

1. Metformin appeared to reduce the incidence of GDM, even though statistically not significant, if continued throughout pregnancy.

2. Also metformin appeared to reduce the need for insulin initiation in patients with GDM. Still statistically found to be non significant.

3. Metformin also appeared to reduce the incidence of hypertensive complications in this study, if given till delivery, but not statistically significant.
4. Metformin also appears to reduce the incidence of preterm labour, again not statistically significant.

5. Metformin appeared to have no role in reducing the incidence of fetal growth restriction as evidenced by this study.

The prevalence of pregnancy complications in our study was lower than in previous reports on PCOS. This can probably be explained by differences in baseline characteristics of the study populations and also by the low sample size.

Previous studies have shown conflicting results, some advocating for the use of metformin due to its beneficial effects and some against its use due to no additional benefits. Despite these favorable effects of metformin use with scarce serious side effects, no definite guidelines recommending metformin use in pregnant women with PCOS exists. According to the findings in this study metformin definitely helps lower the incidence of GDM, and insulin requiring GDM and to some extent, hypertensive complications and preterm labour, and can be safely continued till delivery, however further research on the topic is necessary before setting any guidelines.

\section{Acknowledgements}

I would like to acknowledge my HOD Dr. Sareena Gilvaz, my consultants, Dr Neetha George, Dr Aswath Kumar, Dr Annie Thadicaren, Dr Lola R. And Dr Saley Daniel for helping me with my cases. I would also like to acknowledge the principal and director of this institution. I would also like to thank Dr K. P. Suresh and Dr Sunanda for helping me with the statistical calculations.

\section{References}

1. Dunaif A, Futterweit W, Segal KR, Dobrjansky A. Profound peripheral insulin resistance, independent of obesity, in polycystic ovary syndrome. Diabetes 1989;38:1165-74.

2. Ehrmann DA, Sturis J, Byrne MM, Karrison T, Rosenfield RL, Polonsky KS. Insulin secretory defects in polycystic ovary syndrome. Relationship to insulin sensitivity 
and family history of non-insulin-dependent diabetes mellitus. $J$ Clin Invest 1995;96:520-7.

3. Dunaif A, Segal KR, Shelley DR, Green G, Dobrjansky A, Licholai T. Evidence for distinctive and intrinsic defects in insulin action in polycystic ovary syndrome. Diabetes 1992;41:1257-66.

4. Sills ES, Perloe M, Palermo GD. Correction of hyperinsulinemia in oligoovulatory women with clomiphene-resistant polycystic ovary syndrome: a review of therapeutic rationale and reproductive outcomes. Eur $J$ ObstetGynecolReprodBiol 2000;91:135-41.

5. Kolodziejczyk B, Duleba AJ, Spaczynski RZ, Pawelezyk L. Metformin therapy dereaseshyperandrogenism and hyperinsulinemia in women with polycystic ovary syndrome. FertilSteril 2000;73:1149-54

6. De Leo V, la Marca A, Ditto A, Morgante G, Cianci A. Effects of metformin on gonadotropin-induced ovulation in women with polycystic ovary syndrome. FertilSteril 1999;72:282-5.

7. Moghetti P, Castello R, Negri C, Tosi F, Perrone F, Caputo $\mathrm{M}$, et al. Metformin effects on clinical features, endocrine and metabolic profiles, and insulin sensitivity in polycystic ovary syndrome: a randomized, double-blind, placebo-controlled 6-month trial, followed by open, long-term clinical evaluation. $J \quad$ ClinEndocrinolMetab 2000;85:139- 46.

8. Diamanti-Kandarakis E, Kouli C, Tsianateli $\mathrm{T}$, Bergiele A. Therapeutic effects of metformin on insulin resistance and hyperandrogenism in polycystic ovary syndrome. Eur $J$ EndocrinolMetab 1997;82:4075-79.

9. Ehrmann DA, Cavaghan MK, Imperial J, Sturis J, Rosenfield RL, Polonsky KS. Effects of metformin on insulin secretion, insulin action, and ovarian steroidogenesis in women with polycystic ovary syndrome. $J$ ClinEndocrinolMetab 1997;82:524-30.
10. Glueck CJ, Wang P, Fontaine R, Tracy T, Sieve-Smith L. Metformininduced resumption of normal menses in 39 of 43 $(91 \%)$ previously amenorrheic women with the polycystic ovary syndrome. Metabolism 1999;48:511-519

11. David E. Poly cystic ovarian syndrome. N EnglJ Med 2005; 352: 1223-1236

12. Checa MA, Requena A, Salvador C et al. Insulin sensitizing agents. Use in pregnancy and as therapy in polycystic ovarian syndrome. Human Reprod Update 2005; 11 : 375-390

13. Costello MF, Eden JA. A systematic review of reproductive system effects of metformin with polycytic ovarian syndrome. Fetilsteril 2003; 79: 1-13

14. Vanky E, Salvesen KA, Heimstad R, Fougner KJ, Romundstad P, Carlsen SM 2004 Metformin reduces pregnancy complications without affecting androgen levels in pregnant polycystic ovary syndrome women: results of a randomized study. Hum Reprod 19:1734-1740

15. Vanky E, Stridsklev S, Heimstad R, Romundstad P, Sokogy K, Kleggetveit O, Hjelle S, von Brandis P, Eikeland T, Flo K, Berg KF, Bunford G, Lund A, Bjerke C, Almås I, Berg AH, Danielson A, Lahmami G, Carlsen SM 2010 Metformin vs placebo from first trimester to delivery in polycystic ovary syndrome: a randomized controlled multicenter study. J ClinEndocrinolMetab 95:E448-E45

16. Legro RS, Kunselaman AR, Dodson WC et al. Prevalance and risk factors for type $2 \mathrm{DM}$ and impaired glucose tolerance in PCOS, a prospective controlled study in 254 affected women. J ClinEndocrinolMetab 1999; 84: 164-169.

17. Weerakiat $S$, Srisombut C, Bunaag $P$ et al. Prevalance of type $2 \mathrm{DM}$ and impaired glucose tolerance in Asian women with PCOS. Int J GynecolObstet 2001; 75: 177184. 
18. Haakova L, Cibala D, Rezabek K, Hill M. Pregnancy outcome in women with PCOS and control matched by age and weight. Hum Reprod 2003; 18: 1438-1441

19. Glueck CJ, Bornovali S, Pranikof FJ, Goldenberg NO, DharashirKar S, Wang P. Metformin and gestational diabetes. CurrDiab Rep 2003; 3: 310-312.

20. Hague WM, Davoren PM, Oliver J, Rowan J. Contraindication to use of Metformin. Metformin may be effective in gestational diabetes. $\mathrm{Br}$ Med J 2003; 326: 762.

21. Norman RJ, Kidson WJ, Coneo RC, Zaeharin MR. Metformin and intervention in polycystic ovarian syndrome. Endocrine Society of Australia, the Australian Diabetes Society and Australian Pediatric endocrine group. Am J Aust 2001; 174: 580-583.

22. Nawaz, F., Khalid, R., Naru, T., Rizvi, J. (2008). Does continuous use of metformin throughout pregnancy improve pregnancy outcomes in women with polycystic ovarian syndrome?.Journal of Obstetrics and Gynaecology Research, 34(5), 832-837 